\title{
Quantitation of Megakaryocytic Progenitors in Apheresis Products by Flow Cytometry and Real Time PCR
}

\author{
Leinøe Eva1, Nielsen Kaspar R², Baech John², Steffensen Rudi², Dybkaer Karen ${ }^{3}$, Boegsted Martin ${ }^{3}$ and Johnsen Hans E ${ }^{1,3 *}$ \\ ${ }^{1}$ Department of Haematology, Herlev Hospital, Copenhagen University Hospital, Copenhagen, Denmark \\ ${ }^{2}$ Department of Clinical Immunology, Aalborg Hospital, Aarhus University Hospital, Aalborg, Denmark \\ ${ }^{3}$ Department of Haematology, Aalborg Hospital Science and Innovation Center, Aarhus University Hospital, Aalborg Denmark
}

\begin{abstract}
Background and aims: Quality assessment of autologous peripheral blood stem cell transplantation (PBSCT) may be improved by enumeration of $\mathrm{CD} 34+/ \mathrm{CD} 61+$ megakaryocytic progenitors within the graft. Enumeration of subsets by flow cytometry (FC) has been difficult to standardize because of a low specificity which may arise from platelet or microsphere adherence. We aimed to analyse platelet adherence to haematopoietic stem cells and establish a quantitative real time polymerase chain reaction (RT-qPCR) assay for CD34 and CD61 gene transcripts. The analysis was used to study CD34 and CD61 as predictors for late platelet recovery following PBSCT in nonHodgkin lymphoma (NHL).
\end{abstract}

Material and methods: FC analysis was performed at aphaeresis products harvested for autologous transplantation and confocal microscopy was applied on sorted cells. The clinical evaluation included analysis of the leukapheresis products of 21 consecutive NHL patients treated with high dose therapy and PBSCT. Early recovery was defined as an observed platelet count $>20 \times 10(9) / L$ before day 12 post transplant and late recovery as an observed platelet count $<20 \times 10(9) / L$ after day 12 post transplant. For RT-qPCR analysis CD34+ cells were sorted from thawed leukapheresis products and RNA extracted and reverse transcribed to cDNA for further analysis of CD34 and CD61 mRNA levels using TaqMan probes.

Results: CD34+/CD61+ cells identified by FC were shown to form a specific subset, with no signs of adherent mature platelets. CD34+/CD61+ cells expressed CD61 mRNA transcripts not found in complementary CD34+/ CD61- cells. No positive correlation between FC based enumeration and RT-qPCR analysis estimation of the megakaryocytic progenitor subsets was identified. Evaluation of the clinical impact by comparing samples from 21 patients with early and late platelet recovery revealed no predictive impact for CD61/BACT ( $\beta$-actin), CD34/ BACT or CD61/CD34 mRNA, expression ratios amongst CD34+ sorted cells.

Conclusion and perspective: A specific subset of CD34+/CD61+ cells can be identified by FC and RTqPCR analysis; however enumeration of this subset did not correlate with platelet recovery after PBSCT. Future studies of the predictive value needs to be evaluated in a group of patients with engraftment failure in international collaboration within the European Blood and Marrow Transplantation Group (EBMT).

Keywords: Megakaryocytic progenitors; CD34; CD61; Autograft

Abbreviations: FC: Flow cytometry; RT-qPCR: Quantitative real time polymerase chain reaction; PBSCT: Peripheral blood stem cell transplantation; B-NHL: B-cell non-Hodgkin's lymphoma; HDT: High dose treatment; ACBT: Beta actin; RNA: Ribonucleic acid; GP: Glycoprotein.

\section{Introduction}

The CD34 antigen is a marker of uncommitted and lineage specific haematopoietic progenitors as defined by colony-forming activity as well as engraftment capability [1]. In recent years a simple and reproducible flow cytometry (FC) based assay has been established for enumeration of CD34+ cells [2-6]. The subsequent years have resulted in several publications related to standardization of this analysis as well as the implication of CD34+ cell enumeration on timing of aphaeresis and prediction of blood cell recovery following high dose therapy (HDT) and autologous peripheral blood transplantation (PBSCT) [726]. Recently, it has been proposed that delay in platelet recovery may be predicted by low numbers of megakaryocytic progenitors [27-29]. The understanding of progenitor identification by FC is based on the hierarchic model of haematopoiesis with lineage specific markers present on early and late progenitors in parallel with the
CD34 antigen. As a consequence, a CD34+ gate can be applied during sample analysis and enumerate different uncommitted and committed lineages including megakaryocytic progenitors as CD34+/CD61+ events $[12,14]$. However, several technical questions are related to such identification and enumeration including the effect of freezing and thawing, antibody specificity as well as the potential risk of platelet adherence. The presence of CD34 or CD61 membrane antigens is a consequence of the translation of mRNA transcribed from active genes. Differentiating cells in the progenitor compartment may have the gene

*Corresponding author: Hans E Johnsen, MD, DMSc, Professor, Clinical Haematology, Department of Haematology, Aalborg Hospital Science and Innovation Center, (AHSIC), Aarhus University Hospital, Sdr. Skovvej 15, DK-9000 Aalborg Denmark, Tel: +45 99326875 (Office), +45 41180053 (Mobile); E-mail: haej@rn.dk

Received September 14, 2011; Accepted October 28, 2011; Published November 10, 2011

Citation: Leinoe E, Nielsen KR, John B, Rudi S, Karen D, et al. (2011) Quantitation of Megakaryocytic Progenitors in Apheresis Products by Flow Cytometry and Rea Time PCR. J Stem Cell Res Ther S3:001. doi:10.4172/2157-7633.S3-001

Copyright: $\odot 2011$ Leinoe $\mathrm{E}$, et al. This is an open-access article distributed under the terms of the Creative Commons Attribution License, which permits unrestricted use, distribution, and reproduction in any medium, provided the original author and source are credited. 
turned off resulting in no mRNA transcription; however, the membrane bound protein may still be present. The size of this population depends upon the half time of the CD34 or CD61 mRNA and the translated membrane proteins [30,31]. By help of a single cell analysis we have documented that about $50 \%$ of blood circulating CD34+ cells lack CD34 mRNA expression. However, most primitive progenitors within the CD34+/CD38- compartment have detectable levels of CD34 mRNA (own unpublished data). The aim of this study is first, to analyze if platelet or microsphere adherence may interfere with flow cytometry enumeration and second, to evaluate if RT-qPCR based techniques can estimate the level of blood circulating CD34+/CD61and CD34+/CD61+ progenitors and correlate to FC enumerations and third to perform a small retrospective pilot study to evaluate the discrimination between fast and late platelet recovery in nonHodgkin lymphoma (NHL) patients undergoing HDT and PBSCT for relapse.

\section{Material and Methods}

\section{Patients, treatment and blood recovery}

The scientific protocol was reviewed and approved by the regional ethic committee in Copenhagen/Herlev Denmark. Twentyone consecutive eligible patients with relapsed B-NHL undergoing PBSCT who had available apheresis products at the Department of Haematology, Herlev Hospital, Copenhagen University Hospital were retrospectively included. The treatment strategy included a stepwise procedure (phase I-IV). During phase I, the salvage induction therapy was two-three courses of mini BEAM consisting of BCNU $60 \mathrm{mg} / \mathrm{m} 2$ day 1 , Etoposide $75 \mathrm{mg} / \mathrm{m} 2$ day $2-5$, Ara-C $100 \mathrm{mg} / \mathrm{m} 2$ q12h day2-5, Melphalan $30 \mathrm{mg} / \mathrm{m} 2$ day 6 until maximum tumor reduction. All patients underwent phase II, which included priming with cyclophosphamide and rhG-CSF for stem cell mobilization monitored daily during mobilization and triggered leukapheresis, when blood levels exceeded 20.000/ml. Leukapheresis continued, until a total yield of at least $2 \times 10^{6} \mathrm{CD} 34+$ cells per $\mathrm{kg}$ was harvested by help of a Fenwal CS 3000 Plus Blood Separator (Baxter Deerfield IL, USA). Leukapheresis products were cryopreserved in $10 \%$ DMSO using a controlled rate liquid nitrogen freezer (Planer Ltd Biomed, Sunbury-on-Thames, UK) and stored in liquid nitrogen until autografting. Subsequently patients were treated in phase III with high dose BEAM chemotherapy consisting of BCNU (carmustine) $300 \mathrm{mg} /$ $\mathrm{m} 2$ administered as an infusion over 1 hour on day -6, Etoposide 200 $\mathrm{mg} / \mathrm{m} 2$ once daily on days -5 to -2 , Cytosine Arabinoside intravenously $200 \mathrm{mg} / \mathrm{m} 2$ twice a day on days -5 to -2 , and Melphalan $140 \mathrm{mg} / \mathrm{m} 2$ on day -1 . The autologous stem cell graft was reinfused on day 0 and blood cell recovery detected by daily blood counts. Early platelet engraftment was defined as a platelet count $>20 \times 10$ (9)/L before day 12 post transplant (group I $(\mathrm{n}=11)$ ) and late engraftment defined as a platelet count $<20 \times 10(9) / \mathrm{L}$ observed after day 12 post transplant (Group II $(\mathrm{n}=9))$.

\section{Identification of CD34+ and CD61+ cells in patients}

In each leukapheresis product the frequency of CD34+ cells was enumerated before freezing by the revised NSCL-G standard [7,29,32]. Subsets of CD34+ cells expressing various lineage specific antigens were quantitated from thawed samples of each leukapheresis product. Cells were incubated and double stained with anti-CD34PE clone HPCA-2 anti-CD61 FITC clone RUU-PL 7F12 (Beckton Dickinson Immune system). The analytic strategy included gating of CD34+ cells (Step 1) and subsequent acquisition of a minimum of 1000 CD34+ double stained cells followed by quadrant statistics or histogram analysis (Step 2). The test antibody and the relevant negative control antibody following subtraction of the values enumerated the CD61+ subset $[27,28,33]$.

\section{Sorting of CD34+ cells}

CD34 positive cells were sorted into CD34+/CD61+ and CD34+/ CD61- cells by a FASC Vantage Cell Sorter (BDIS) equipped with an automated cell position unit (ACDU, permitting single-cell sorting with an accuracy more than 99\%) and a Coherent Enterprise laser tuned at $488 \mathrm{~nm}(100 \mathrm{~mW})$ into individual PCR tubes of a 96-well PCR plate (Sorensen Bioscience Inc., Salt Lake City, Utah USA). Each tube held $5 \mu \mathrm{l}$ of DEPC-treated water that contained $1 \mu \mathrm{g}$ of E-coli transfer ribonucleic acid (tRNA, Sigma Chemical Co Copenhagen Denmark).

\section{Sample handling for flow cytometry and RT-qPCR analysis}

From each product samples of 1-2 x 10 $0^{7}$ nucleated cells in DMSO were frozen in small plastic tubes and stored at $-80^{\circ} \mathrm{C}$ until analysis. At the time of analysis, the samples were thawed in a pre-warmed $41^{\circ} \mathrm{C}$ water bath adding PBS with $1 \mathrm{mM}$ EDTA in accordance with published practice [27-29]. Following the washing procedures mononuclear cells were counted and used for the FC and/or RT-qPCR analysis. A prerequisite for such analysis is that the freezing and thawing procedure does not induce relative changes within the CD34+ cell compartment. In an analysis of 14 samples analyzed at the time of harvest and following thawing we found the CD34\% of $1.4 \%$ (0.2-5.3\%) and $2.0 \%$ (0.2-7.5\%), respectively due to a selective loss of granulocytes present in the fresh product.

However, the CD34+/CD61+ was 7.5\% (1-15\%) and 8.5\% (2-29\%), respectively, indicating no significant selective loss of lineage specific subsets (data not shown).

\section{RNA extraction from cells}

RNA was extracted from frozen cells with the RNAeasy mini kit (Qiagen GMbh, Hilden, Germany) according to the manufacture protocol. The RNA was eluted into $30 \mu \mathrm{H}_{2} 0$.

\section{Quantitative CD61 RT-qPCR with TaqMan technique}

RT-qPCR analysis was performed as a two-step RT-qPCR using TaqMan probes selected to span exon-intron boundaries using predeveloped TaqMan assay id Hs00173978_m1 for the CD61 transcript, Hs00156373_m1 for CD34 transcript and 433762T for the human endogenous control, beta-actin (ACTB). All reaction was performed in an ABI PRISM 7000 Sequence detector and data were collected and analyzed with the sequence detector software version 1.1 (Applied Bio systems, Foster City, CA, USA).

\section{Statistical analysis}

Fold-changes and their confidence intervals between patient groups are calculated on a log- scale but results are transformed back to linear scale and reported. Comparisons between patient groups were performed by unpaired Student's t-tests. Correlations analysis was performed by Spearman's test for vanishing rank correlation coefficients. Differences between groups resulting in p-values below 0.05 were considered significant. 


\section{Results}

Analysis of platelet adherence to stem cells by confocal microscopy, RT-qPCR and FC

Single CD34+/CD61+ or CD34+/CD61- cells were sorted and visualized in the microscope with a diffuse membrane staining for CD34PE (red) in both subsets and a differentiated CD61 FITCH (green) staining with no indication of platelet adherence (Figure 1). The sorted subsets were further analyzed by RT-qPCR showing that the CD34+/CD61+ cells expressed CD61 mRNA at a much higher level compared to CD34+/CD61- cells (Figure 2). The presence of the late platelet differentiation marker CD42b on $\mathrm{CD} 34+/ \mathrm{CD} 61+$ positive cells were analyzed by FC and revealed a median value of $79 \%(\mathrm{~N}=7$, range 33-94\%).

\section{Quantitation of CD34 and CD61 mRNA with RT-qPCR}

The CD34 mRNA ratio normalized to the $\beta$-actin (BACT) mRNA level were quantitated in samples from $21 \mathrm{~B}$-NHL patients and compared to the $\mathrm{CD} 34$ enumeration by flow cytometry resulting in a significant correlation (Figure 3A; p-value $<0.01$, Spearman's test). Quantitation of the CD61 mRNA normalized to the ribosomal RNA level in leukapheresis samples were compared to the relative number of CD61+ events by flow cytometry which did not correlate (Figure 3B) (not significant). This was further supported by analysis of seven different autografts purified for CD34+ cells by magnetic field selection (Table 1), which also deplete for potential contaminating CD61 positive platelets. These results indicate that there is no correlation between cytometry and gene expression levels for CD61.

\section{Impact on time to platelet recovery}

Evaluation of the clinical impact of quantitation of CD61 transcripts was performed by comparing flow sorted CD34+ apheresis samples from group I (early) and II (late) defined by platelet recovery as described, and resulted in a CD61/BACT ratio of the geometric means between groups I and II of 1.20 (95\%CI: 0.31; 4.61; non-signinficant)
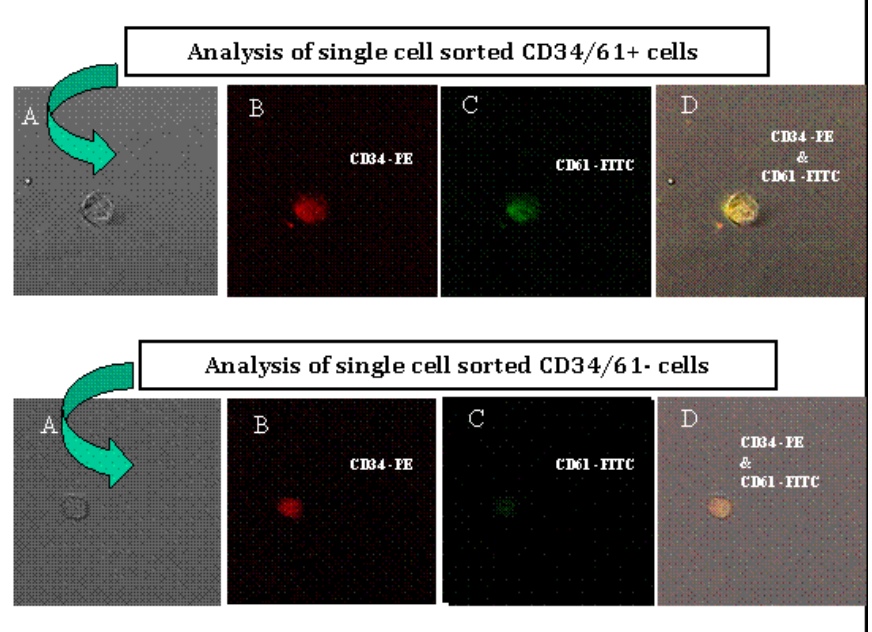

Figure 1: Confocal microscopy of single sorted CD34+/CD61+ and CD34+ CD61- cells. Legend: Microscopy of CD34+/CD61+ and CD34+/CD61- sorted single cells (picture A). Sorted cells were analyzed at the single cell level as illustrated by one representative experiment which show CD34PE (red) stained cells (picture B), CD61FITC differential stained cells (picture C) and combined CD34PE \& CD61FITC stained cells (picture D).

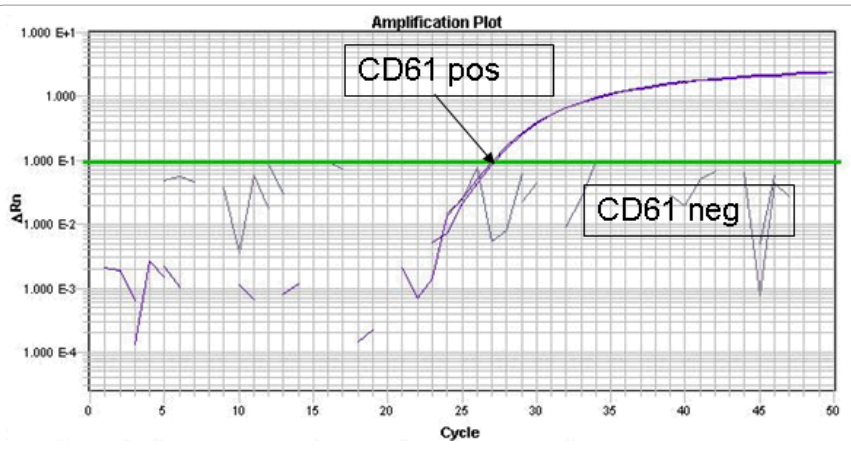

Figure 2: RT-qPCR for CD61 gene expression in sorted CD34+/CD61+and CD34+/CD61-cells. Legend: Fluorescence intensity for CD61 transcripts in sorted subsets, illustrating differential expression as expected. Two CD61 positive representative experiments are shown. CD61 negative cells are belowe the green line.

A

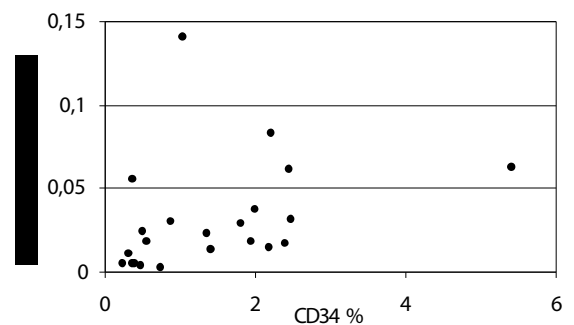

B

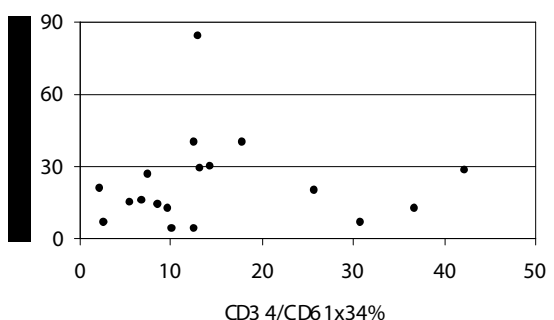

Figure 3AandB: Correlation between flow cytometry enumeration and gene expression in $21 \mathrm{NHL}$ patients. Legend: Figure A shows correlation between CD34 gene expression (normalized CD34 mRNA) and number of CD34 positive cells (CD34\%) ( $P$ - value $<0.01$, Spearman's test) and Figure $B$ correlation between CD61 gene expression (CD61 mRNA ratio) and number of CD61+/CD34+ \% x CD34\% (not significant). Because of shortage of material there are only 18 patients in this group.

see Figure 4a. For CD34/BACT, the ratio of the geometric means between group I and II was 0.63 (95\%CI: 0.16; 2.41; non-significant) see Figure 4b. For CD61/CD34, the ratio of the geometric means between groups I and II was 1.91 (95\%CI: 0.67; 5.44; non-significant see Figure 4c. In this small pilot study it is concluded that CD34 and/or CD61 gene expression as predictor for platelet recovery did not alone add new information to assessment of autograft quality.

\section{Discussion}

A clinical problem in supportive PBSCT is the occurrence of prolonged time to platelet recovery, which by several publications has been associated to the presence of megakaryocytic progenitors identified as CD34+/CD61+ or CFU Meg+ cells by flow cytometry or culture assays respectively $[27,28,33]$. Consequently, quality assessment of stem cell grafts may be improved by enumeration of such cells. 
Colony forming cells are difficult and time consuming to enumerate and therefore FC enumeration has been established and standardised [29].

However, several theoretical and technical questions are related to such identification and enumeration. In theory the membrane integrin aIIb $\beta 3$, also known as glycoprotein (GP) IIb/IIIa or CD61 may be used to identify megakaryocytic progenitors by FC, due to its expression early in the stem cell maturational sequence and retain throughout megakaryocytic and platelet differentiation $[34,35]$. CD61 has different

\begin{tabular}{|c|c|}
\hline Flow Cytometry Enumeration & RT-qPCR Normalized Ratio \\
\hline CD61+/CD34+ $\%$ & CD61 mRNA \\
\hline 3,17 & 1,83 \\
\hline 2,15 & 17,65 \\
\hline 0,90 & 0,14 \\
\hline 0,85 & 0,25 \\
\hline 0,28 & 0,43 \\
\hline 0,25 & 0,07 \\
\hline 0,14 & 0,28 \\
\hline
\end{tabular}

Table 1: Analysis of CD61 gene expression in microbeads enriched CD34+ autografts. Legend: Study of CD34+ magnetic field selected autograft samples analyzed for CD61+/CD34+\% by flow cytometry (ranked) and for CD61 gene expression by RT-qPCR.

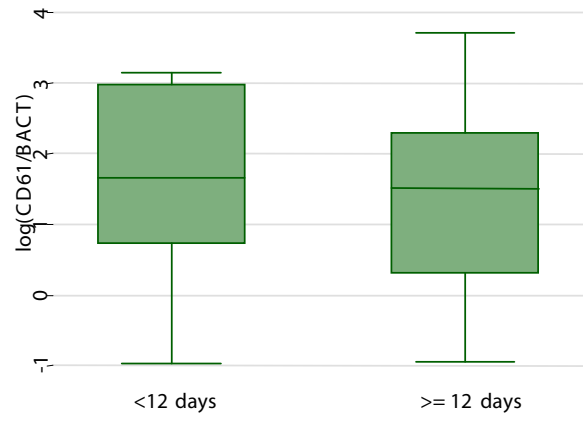

Figure 4a: Days with platelet count $<20^{*} 10^{9} / /$ compared to CD61/BACT mRNA ratio. Group I: Platelet count $>20 \times 10(9) / L$ before day 12 post transplant $(n=11)$. Group II: Platelet count $<20 \times 10(9) / L$ observed from day 12 post transplant $(n=9)$.

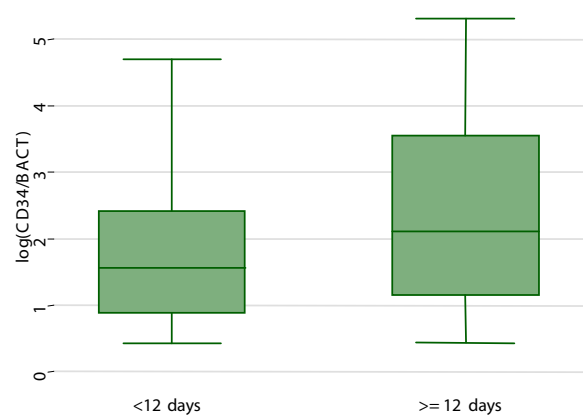

Figure 4b: Days with platelet count $<20^{*} 10^{9} / \mathrm{l}$ compared to CD34/BACT mRNA ratio. Group I: Platelet count $>20 \times 10(9) / L$ before day 12 post transplant $(n=11)$ Group II: Platelet count <20x10(9)/L observed from day 12 post transplant $(n=9)$.

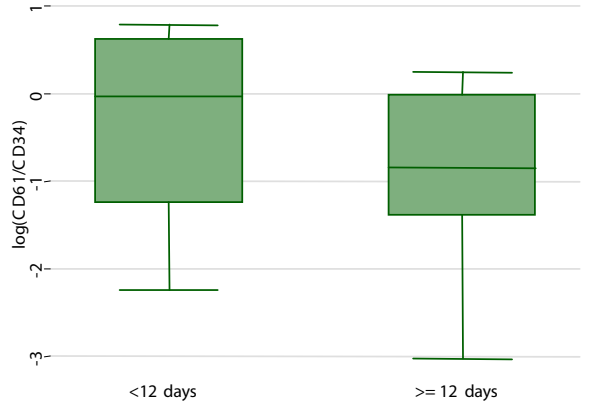

Figure 4c: Days with platelet count $<20^{*} 10^{9} / /$ compared to by CD61/CD34 mRNA ratio. Group I: platelet count $>20 \times 10(9) / L$ before day 12 post transplant $(n=11)$. Group II: platelet count $<20 \times 10(9) / L$ observed from day 12 post transplant $(n=9)$.

functions depending on the stage of differentiation. Initially, it is considered to mediate adhesion of megakaryocytes and its progenitors to bone marrow matrix and later it is essential for platelet aggregation and inside-out signalling [36-41] The molecule has been identified on very early bipotent erythro-megakaryocyte progenitors, however, increasing in density with differentiation into the megakaryocytic lineage $[41,42]$. Another lineage specific marker is GPIba or CD42b, a part of the von Willebrand factor receptor complex (GPIb-V-IX) which is present on platelets but markedly delayed in committed cells compared to CD61 [43-45].

Identification of CD61+ cells by FC is a technical different matter due to the presence of potential cell adhering platelets, which by random may interfere with identification and enumeration $[27,28]$. This phenomenon has been circumvented by adding EDTA to the washing buffer, since P-selectin mediated platelet adhesion is reversible and $\mathrm{Ca}^{++}$dependent $[27,28]$.

To support this strategy and the definition of the FC identified progenitor population, this study has made use of cell sorting and RT-qPCR analysis in a series of experiments which should reject the possibility, that the CD61+ platelet adherence was involved as false positive identification of CD34+/CD61+ progenitors. Morphological analysis by confocal microscopy of sorted cells did not reveal platelet adherence as a potential problem (Figure 1). Extended FC analysis for CD42b did identify CD42b expression "on the majority" of $\mathrm{CD} 34+/ \mathrm{CD} 61+$ megakaryocytic progenitors. Consequently, CD42b enumeration did not enable us to exclude the possibility of platelet adherence to CD34+ progenitors. Further, sorted CD34+/CD61+ cells expressed CD61 mRNA not found in CD34+/CD61- cells, strongly indicating that the CD61 gene is turned on at least in a fraction of CD34+/CD61+ cells. Finally, the correlation between FC enumeration and RT-qPCR was performed in $21 \mathrm{~B}-\mathrm{NHL}$ leukapheresis products concluding that the positive correlation seen for CD34 membrane protein and mRNA was not found for CD61. The explanation for this difference is not obvious but it is temptating to speculate if this is a consequence of the varying pattern and complexity of growth factor control of early and late progenitors including uncommitted CD34+ and lineage specific CD34+/CD61+ progenitors

In summary, the recommended methodology for CD34+/CD61+ cell enumeration by flow cytometry has previously been used in retrospective studies documenting clinical impact $[27,28,33]$. However, 
before moving into prospective multicenter EBMT studies we have rejected the possibility, that the $\mathrm{CD} 61+$ platelet adherence may be involved as false positive identification of megakaryocytic progenitors as CD34/CD61+ cells and supported the FC defined identification. Finally, we found no positive correlation between FC and RT-qPCR estimation of the progenitor subsets, supporting that the latter should be studied as a variable of importance for quality assessment with focus on patients at risk for graft failure.

\section{References}

1. Krause DS, Fackler MJ, Civin Cl, May WS (1996) CD34: structure, biology, and clinical utility. Blood 87: 1-13.

2. Inaba T, Shimazaki C, Ashihara E, Ohkawa K, Oku N, et al. (1992) Twocolor flow cytometric analysis of CD34-positive peripheral blood stem cells mobilized by recombinant human granulocyte- colony stimulating factor for autotransplantation. Prog Clin Biol Res 377: 561-567.

3. Read EJ, O'Shaughnessy JA, Yu MY, Cottler-Fox M, Denicoff AM, et al. (1992) Flow cytometric quantitation of circulating hematopoietic progenitor cells in breast cancer patients on chemotherapy. Prog Clin Biol Res 377: 523-530.

4. Bender JG, Williams SF, Myers S, Nottleman D, Lee WJ, et al. (1992) Characterization of chemotherapy mobilized peripheral blood progenitor cells for use in autologous stem cell transplantation. Bone Marrow Transplant 10: 281-285.

5. Siena S, Bregni M, Brando B, Belli N, Lansdorp PM, et al. (1991) Flow cytometry to estimate circulating hematopoietic progenitors for autologous transplantation: comparative analysis of different CD34 monoclonal antibodies. Haematologica 76: 330-333.

6. Civin Cl, Strauss LC, Brovall C, Fackler MJ, Schwartz JF, et al. (1984) Antigenic analysis of hematopoiesis III. A hematopoietic progenitor cell surface antigen defined by a monoclonal antibody raised against KG-1a cells. J Immunol 133: 157-165.

7. Johnsen HE, Knudsen LM (1996) Nordic flow cytometry standards for CD34+ cell enumeration in blood and leukapheresis products: report from the second Nordic Workshop. Nordic Stem Cell Laboratory Group (NSCL-G). J Hematother 5: 237-245.

8. Wunder E, Sovalat H, Fritsch G, Silvestri F, Henon P, et al. (1992) Report on the European Workshop on Peripheral Blood Stem Cell Determination and Standardization--Mulhouse, France, February 6-8 and 14-15, 1992. J Hematother 1: 131-142.

9. Bender JG, Unverzagt KL, Walker DE , Lee W, Lum L, et al. (1992) Characterization of CD34+ cells mobilized to the peripheral blood during the recovery from cyclophosphamide chemotherapy. Prog Clin Biol Res 377: 575582.

10. Fritsch G, Emminger W, Buchinger P, Printz D, Gadner H (1992) CD34 analysis in peripheral blood correlates with colony forming capacity--an update. Prog Clin Biol Res 377: 531-536.

11. Sovalat H, Wunder E, Tienhaara A, Olofsson T, Fritsch G, et al. (1993) Commentary: prospects for standardization of stem cell determination within Europe. J Hematother 2: 293-296.

12. Di Nicola M, Siena S, Bregni M, Peccatori F, Magni M, et al. (1993) Quantization of CD34+ peripheral blood hematopoietic progenitors for autografting in cancer patients. Int J Artif Organs 16: 80-82.

13. Urashima M, Ohkawara J, Hoshi Y, Kato Y, Uchiyama H, et al. (1994) Peripheral blood progenitor cell transplantation estimated by three-colour (CD34, HLADR, CD33) flow cytometry. Acta Haematol 92: 23-28.

14. Zimmerman TM, Lee WJ, Bender JG, Mick R, Williams SF (1995) Quantitative CD34 analysis may be used to guide peripheral blood stem cell harvests. Bone Marrow Transplant 15: 439-444.

15. Lowdell MW (1996) Bainbridge DR. External quality assurance for CD34 cell enumeration-- results of a preliminary national trial. Royal Microscopical Society Clinical Flow Cytometry Group QA Schemes. Bone Marrow Transplant 17: 849-853.
16. Serke S, Arseniev L, Watts M, Fritsch G, Ingles-Esteve J, et al. (1997) Imprecision of counting CFU-GM colonies and CD34-expressing cells. Bone Marrow Transplant 20: 57-61.

17. Macey MG, McCarthy DA, van Agthoven A, Newland AC, et al. (1997) How should CD34+ cells be analysed? A study of three classes of antibody and five leucocyte preparation procedures. J Immunol Methods 204: 175-188.

18. Lumley MA, McDonald DF, Czarnecka HM, Billingham LJ, Milligan DW (1996) Quality assurance of CD34+ cell estimation in leucapheresis products. Bone Marrow Transplant 18: 791-796.

19. Brecher ME, Sims L, Schmitz J, Shea T, Bentley SA (1996) North American Multicenter Study on flow cytometric enumeration of CD34+ hematopoietic stem cells. J Hematother 5: 227-236.

20. Sutherland DR, Anderson L, Keeney M, Nayar R, Chin-Yee I (1996) The ISHAGE guidelines for $\mathrm{CD} 34+$ cell determination by flow cytometry. International Society of Hematotherapy and Graft Engineering. J Hematother 5: 213-226.

21. Knape CC (1996) Standardization of absolute CD34 cell enumeration [letter comment]. J Hematother 5: 211-212.

22. Schots R, Van Riet I, Damiaens S, Flament J, Lacor P, et al. (1996) The absolute number of circulating CD34+ cells predicts the number of hematopoietic stem cells that can be collected by apheresis. Bone Marrow Transplant 17: 509-515.

23. Ravagnani F, Siena S, Bregni M, Brando B, Belli N, et al. (1991) Methodologies to estimate circulating hematopoietic progenitors for autologous transplantation in cancer patients. Haematologica 76: 46-49.

24. Serke S, Sauberlich S, Huhn D (1991) Multiparameter flow-cytometrica quantitation of circulating CD34(+)-cells: correlation to the quantitation of circulating haemopoietic progenitor cells by in vitro colony-assay. $\mathrm{Br} \mathrm{J}$ Haematol 77: 453-459.

25. Weaver CH, Hazelton B, Birch R, Palmer P, Allen C, et al. (1995) An analysis of engraftment kinetics as a function of the CD34 content of periphera blood progenitor cell collections in 692 patients after the administration of myeloablative chemotherapy. Blood 86: 3961-3969.

26. Wunder E, Sovalat H, Henon P, Serke S (1994) Hematopoietic Stem Cells. The Mulhouse Manual In: Alpha Med Press: 1-317

27. Dercksen MW, Weimar IS, Richel DJ, Breton-Gorius J, Vainchenker W, et al (1995) The value of flow cytometric analysis of platelet glycoprotein expression of CD34+ cells measured under conditions that prevent P-selectin-mediated binding of platelets. Blood 86: 3771-3782.

28. Dercksen MW, Rodenhuis S, Dirkson MK, Schaasberg WP, Baars JW, et al. (1995) Subsets of CD34+ cells and rapid hematopoietic recovery after peripheral-blood stem-cell transplantation. J Clin Oncol 13: 1922-1932.

29. Johnsen HE, Baech J, Nicolaisen K (1999) Validation of the Nordic Flow Cytometry Standard for CD34+ Cell Enumeration in Blood and Autografts: Report from the Third Workshop. J Hematother 8: 15-28.

30. Nakamura $Y$, Komano $H$, Nakauchi $H$ (1993) Two alternative forms of cDNA encoding CD34. Exp Hematol 21: 236-242.

31. Suda J, Sudo T, Ito M, Ohno N, Yamaguchi Y, et al. (1992) Two types of murine CD34 mRNA generated by alternative splicing. Blood 79: 2288-2295.

32. Johnsen HE (1995) Report from a Nordic workshop on CD34+ cell analysis: technical recommendations for progenitor cell enumeration in leukapheresis from multiple myeloma patients. Nordic Myeloma Study Group Laboratories. J Hematother 4: 21-28.

33. Knudsen LM, Jensen L, Jarlbaek L, Hansen PG, Hansen SW, et al. (1999) Subsets of $\mathrm{CD} 34+$ hematopoietic progenitors and platelet recovery after high dose chemotherapy and peripheral blood stem cell transplantation. Haematologica 84: 517-524.

34. Levene RB, Lamaziere JM, Broxmeyer HE, Lu L, Rabellino EM (1985) Human megakaryocytes. V. Changes in the phenotypic profile of differentiating megakaryocytes. J Exp Med 161: 457-474.

35. Tomer A, Harker LA, Burstein SA (1988) Flow cytometric analysis of norma human megakaryocytes. Blood 71: 1244-1252. 
Citation: Leinoe E, Nielsen KR, John B, Rudi S, Karen D, et al. (2011) Quantitation of Megakaryocytic Progenitors in Apheresis Products by Flow Cytometry and Real Time PCR. J Stem Cell Res Ther S3:001. doi:10.4172/2157-7633.S3-001

36. Debili N, Coulombel L, Croisille L, Katz A, Guichard J, et al. (1996) Characterization of a bipotent erythro-megakaryocytic progenitor in human bone marrow. Blood 88: 1284-1296.

37. Wickenhauser C, Schmitz B, Baldus SE, Henze F, Farahmand P, et al. (2000) Selectins (CD62L, CD62P) and megakaryocytic glycoproteins (CD41a, CD42b) mediate megakaryocyte-fibroblast interactions in human bone marrow. Leuk Res 24: 1013-1021.

38. Zauli G, Bassini A, Vitale M, Gibellini D, Celeghini C, et al. (1997) Thrombopoietin enhances the alpha Ilb beta 3-dependent adhesion of megakaryocytic cells to fibrinogen or fibronectin through PI 3 kinase. Blood 89: 883-895.

39. Mossuz P, Schweitzer A, Molla A, Berthier R (1997) Expression and function of receptors for extracellular matrix molecules in the differentiation of human megakaryocytes in vitro. $\mathrm{Br} \mathrm{J}$ Haematol 98: 819-827.

40. Shattil SJ, Hoxie JA, Cunningham M, Brass LF (1985) Changes in the platelet membrane glycoprotein Ilb.IIla complex during platelet activation. J Biol Chem 260: 11107-11114
41. Payrastre B, Missy K, Trumel C, Bodin S, Plantavid M, et al. (2000) The integrin alpha Ilb/beta 3 in human platelet signal transduction. Biochem Pharmacol 60:1069-1074.

42. Clemetson KJ, Clemetson JM (1995) Platelet GPIb-V-IX complex. Structure function, physiology, and pathology. Semin Thrombus Hemost 21: 130-136.

43. Okumura N, Tsuji K, Nakahata T (1992) Changes in cell surface antigen expressions during proliferation and differentiation of human erythroid progenitors. Blood 80: 642-650.

44. Tomer A (2004) Human marrow megakaryocyte differentiation: multiparameter correlative analysis identifies von Willebrand factor as a sensitive and distinctive marker for early ( $2 \mathrm{~N}$ and $4 \mathrm{~N}$ ) megakaryocytes. Blood 104: 2722-2727.

45. LePage A, Leboeuf M, Cazenave JP, de la Salle C, Lanza F, et al. (2000) The alpha(Ilb)beta(3) integrin and GPIb-V-IX complex identify distinct stages in the maturation of CD34(+) cord blood cells to megakaryocytes. Blood 96: 41694177

This article was originally published in a special issue, Hematopoietic stem cell transplantation handled by Editor(s). Dr. Porrata Luis F, Mayo Clinic Transplant Center, USA 